\title{
Châtillon-sur-Loire - Chenoy
}

$\mathrm{n}^{\circ} 064523$

Jean-Pierre Halley

\section{(2) OpenEdition}

Journals

Édition électronique

URL : http://journals.openedition.org/adlfi/14308

ISSN : 2114-0502

Éditeur

Ministère de la culture

Référence électronique

Jean-Pierre Halley, «Châtillon-sur-Loire - Chenoy », ADLFI. Archéologie de la France - Informations [En ligne], Centre, mis en ligne le 20 mars 2015, consulté le 03 mai 2019. URL : http:// journals.openedition.org/adlfi/14308

Ce document a été généré automatiquement le 3 mai 2019.

(c) Ministère de la Culture et de la Communication, CNRS 


\section{Châtillon-sur-Loire - Chenoy}

$n^{\circ} 064523$

Jean-Pierre Halley

Lien Atlas (MCC) :

http://atlas.patrimoines.culture.fr/atlas/trunk/index.php?

ap_theme=DOM_2.01.02\&ap_bbox=2.684;47.536;2.803;47.615

1 Les vols en ULM de 1996 et 1997 avaient révélé le tracé de certaines voies romaines ainsi que de nombreuses zones dites "à semis » ou "micro-reliefs » ou "mouchetures » proches de ces voies et étendues sur plusieurs hectares avec un diamètre estimé de 2 à $3 \mathrm{~m}$.

2 L'hypothèse avancée était celle d'une voie construite en minerai de fer, abondant dans la région, et de puits d'extraction de ce minerai à faible profondeur.

3 La tranchée n'a rien confirmé sinon la présence d'une zone de sablon ocré ferreux très compactable, humide et offrant une forte imperméabilité à l'eau. Il est encore très exploité dans la région. Ce sablon aurait été aussi exploité dans l'Antiquité pour sa forte teneur en fer.

INDEX

Index géographique : Centre, Loiret (45), Châtillon-sur-Loire

operation Sondage (SD)

Index chronologique : Gallo-romain

Mots-clés : voie 